\title{
A QUALIDADE CALMANTE PERCEBIDA EM CENAS DE RECEPÇÕES HOSPITALARES
}

\author{
MACIEL, Ana Maria M. (1); \\ COSTA FILHO, Lourival (2); \\ VILLAROUCO, Vilma (3) \\ (1) UFPE / PPGDesign, Mestre em Gestão Pública \\ e-mail:anamariamaciel@yahoo.com.br \\ (2) UFPE / PPGDesign, Doutor em Desenvolvimento Urbano \\ e-mail: lourivalcosta@yahoo.com \\ (3) UFPE / PPGDesign / PPErgo, Doutora em Engenharia de Produção, \\ e-mail:villarouco@hotmail.com

\begin{abstract}
RESUMO
A pesquisa apresentada teve como objetivo avaliar a qualidade calmante percebida em cenas de recepção hospitalar. Foi utilizada uma sentença mapeadora geral, procedimento básico da Teoria das Facetas, para estruturar a investigação empírica que elegeu o questionário online para coletar os dados, interpretados através de uma tabela de distribuição das frequências. Os resultados empíricos confirmaram os postulados teóricos para a qualidade calmante percebida.
\end{abstract}

Palavras-chave: recepção hospitalar; qualidade calmante; ergonomia do ambiente construído.

\begin{abstract}
The research presented aimed to assess perceived calming quality of different scenes in hospital receptions. A general mapping sentence, which is a basic procedure of Facet Theory, was used to structure the empirical investigation, which used an online questionnaire to collect the data, and which was interpreted through a frequency distribution table. The empirical findings confirmed the theoretical postulates theories of perceived calming quality.
\end{abstract}

Keywords: hospital reception; calming quality; ergonomics of the built environment.

\section{INTRODUÇÃO}

As pessoas tendem a ficar angustiadas quando se encontram doentes e precisam procurar e aguardar por atendimento médico. Nessas situações, geralmente estressantes, ambientes de recepção hospitalar com elementos estimulantes e/ou excitantes podem ser inadequados e tornar a experiência muito desagradável. Em sentido inverso, ambientes desestimulantes e/ou calmantes parecem ser mais agradáveis no enfrentamento da situação problematizada.

A partir desse contexto estratégico, a pesquisa estruturou sua abordagem considerando que os ambientes de recepção hospitalar devem ter qualidade calmante para serem percebidos como adequados aqueles que precisam esperar para receber atenção médica. 


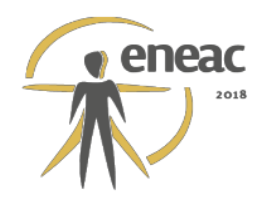

Para Villarouco (2011), contudo, as variáveis envolvidas na identificação da adequabilidade de um ambiente construído são muitas, o que torna a tarefa de aferir essa adequação muito complexa, notadamente quando é encarada sob o enfoque da ergonomia, visto que essa disciplina não estuda o ambiente considerando apenas variáveis físicas, utilizando também outras de diferentes campos do conhecimento, como, por exemplo, da psicologia ambiental.

A qualidade calmante percebida é um construto psicológico: envolve julgamentos subjetivos. Tais julgamentos consideram referências do ambiente ou dos sentimentos das pessoas sobre os ambientes. Os primeiros são chamados de julgamentos perceptuais/cognitivos e os segundos de julgamentos afetivos. Embora a qualidade calmante possa depender, em parte, de fatores perceptuais/cognitivos, é, por definição, um julgamento emocional que envolve avaliação e sentimentos. Como resultado, a qualidade calmante percebida foi medida aqui através de julgamentos avaliativos dos ambientes de recepção hospitalar.

Duas características relacionadas com os ambientes de recepção hospitalar - coerência e complexidade - foram escolhidas para estudo pelas suas prováveis influências na qualidade calmante percebida. Conforme Kaplan (1988), a coerência é explicada como o grau em que os elementos ambientais se encaixam enquanto a complexidade é entendida como a quantidade de variação dos elementos ambientais nas cenas.

Logo, a pesquisa aqui apresentada teve como objetivo - a partir de um referencial teórico baseado no conceito de preferência ambiental de Kaplan (1988) e na qualidade afetiva de ambientes proposta por Russel (1988) - avaliar a qualidade calmante percebida em cenas de ambientes de recepção hospitalar.

Os estudos nessa área se justificam para a ergonomia do ambiente construído no sentido de prover informações empíricas da melhoria da adequabilidade dos projetos de ambientes de recepção hospitalar às necessidades psicológicas dos usuários/pacientes, pois de acordo com Nasar (2000), pesquisa aponta que as características dos elementos de um ambiente têm importantes impactos na experiência humana, podendo evocar fortes emoções como agrado ou desagrado, atuar como efeito estressante ou restaurador (calmante) e possibilitar inferências sobre lugares e pessoas. Podem também influenciar o comportamento humano, de modo que as pessoas estão mais propensas a ir e permanecer em locais que percebem favoravelmente, e evitam outros que percebem desfavoráveis.

Apesar das respostas avaliativas, por si só, não poderem prever o comportamento real, a avaliação combinada de respostas avaliativas e do comportamento previsto dá uma boa indicação do comportamento real (NASAR, 1988). Por essa razão, na presente pesquisa, os participantes foram convidados a indicar em que medida vários ambientes de recepção hospitalar favorecem a espera por atendimento médico, objetivando a avaliação.

\section{A DEFINIÇÃO DA QUALIDADE CALMANTE PERCEBIDA}

Ao avaliar um ambiente, as pessoas julgam a qualidade visual (aparência estética) antes de qualquer outra coisa da sua configuração física.

Os estímulos do ambiente, muitos deles pouco notados conscientemente, moldam nossos sentimentos, pensamentos e comportamento. Por essa razão, a qualidade visual tem importantes impactos sobre a experiência humana, podendo afetar a produtividade do trabalhador, o comportamento do consumidor e o resultado final esperado (NASAR, 2000).

A qualidade visual percebida em ambientes foi descrita como o produto da necessidade humana de ser envolvido e da necessidade de a cena fazer sentido (KAPLAN, 1988). O ambiente deve ser "envolvente" para atrair a atenção humana, assim como "fazer sentido" para que se possa operar nele. A complexidade e a coerência, ainda para o mesmo autor, desempenham papéis importantes na satisfação dessas necessidades humanas. 


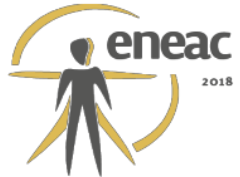

A complexidade provoca envolvimento e tal relação, por um lado, tem sido consistentemente apoiada por achados empíricos para medidas de envolvimento, como, por exemplo, tempo de procura e interesse (WOHLWILL, 1976). Por outro lado, o tom hedônico (agradabilidade ou beleza) foi postulado como tendo a forma de um "U" invertido para a complexidade. O aumento da complexidade eleva o tom hedônico até certo ponto e depois decai. Baixa complexidade é monótona e entediante; alta é caótica e estressante (WOHLWILL, 1976). O nível médio de complexidade parece ser o mais agradável (NASAR, 2000). Os achados empíricos para a complexidade, entretanto, ainda têm sido inconsistentes, talvez por causa dos procedimentos metodológicos (KAPLAN, 1988; WOLHWILL, 1976). Alguns estudos, segundo Nasar (1988), não conseguiram controlar covariáveis naturais da complexidade, como dilapidação, postes/fios e vegetação; outros não usaram uma gama de complexidade suficiente para que a desaceleração da agradabilidade surgisse.

Para a cena fazer sentido, deve ser compreendida. Ao facilitar a compreensão, a coerência deve reduzir a incerteza e aumentar o tom hedônico (KAPLAN, 1988; WOHLWILL, 1976). Tal relação tem sido consistentemente confirmada em pesquisas empíricas (NASAR, 1988).

A literatura indica que a complexidade e a coerência (obtida aqui através das reduções do contraste) podem influenciar a qualidade calmante nos ambientes de recepção hospitalar de formas previsíveis. A complexidade deve aumentar o estímulo (reduzindo a calma) e a coerência deve reduzir o estímulo (aumentando a calma). A qualidade calmante deve ser aumentada através da complexidade moderada e da coerência alta (baixo contraste). Como uma evidência empírica, baseando-se nos achados de Russel (1988), a qualidade calmante percebida foi medida nesta pesquisa através dos julgamentos avaliativos para várias cenas de ambientes de recepção hospitalar.

A obtenção de satisfação espacial depende de diferentes objetivos de qualidade visual relacionados às atividades e à função do ambiente, como postula a ergonomia do ambiente construído. Alguns ambientes devem parecer atraentes; outros empolgantes ou calmos. Em suma, o clima emocional do ambiente deve variar para se ajustar aos objetivos da atividade.

Cabe, ainda, destacar que a qualidade visual percebida considera as experiências e as opiniões de não-especialistas com o ambiente, e não aquelas de especialistas no assunto. Por essa razão, a qualidade visual percebida será favorável se um número significativo de nãoespecialistas assim perceberem. Caso especialistas e não especialistas experienciassem regularmente determinado ambiente e compartilhassem valores estéticos, ou fosse possível medir com precisão as necessidades estéticas das pessoas, a confiança em instituições profissionais poderia ser aceita. Pesquisas infelizmente indicam que os especialistas diferem dos não-especialistas no que diz respeito às preferências ambientais (NASAR, 1988).

\section{CONSIDERAÇÕES METODOLÓGICAS}

As relações entre os diversos aspectos da experiência das pessoas com um determinado ambiente podem ser sumarizadas através de uma sentença mapeadora geral (general mapping sentence), instrumento básico da Teoria das Facetas, que liga as facetas e resulta em uma frase norteadora para o desenho do instrumento de coleta de dados. Como tal, reflete a hipótese sobre as relações entre os elementos internos das facetas, sendo precisamente essas relações que serão testadas na situação empírica (COSTA FILHO, 2016). Investigações empíricas desenvolvidas nessa linha têm produzido resultados cumulativos que vêm ajudando, paulatinamente, a reforçar ou refutar aspectos dos modelos teóricos de avaliação e do lugar (COSTA FILHO, 2014).

O Quadro 1 apresenta a sentença mapeadora geral proposta para a avaliação da qualidade calmante percebida de ambientes de recepção hospitalar, com três tipos de facetas. O primeiro tipo se refere ao grupo pesquisado. O segundo tipo diz respeito ao conteúdo das variáveis 


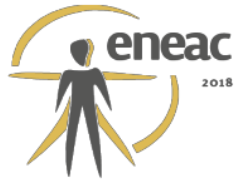

pesquisadas. Juntas, essas duas facetas determinam o campo de interesse da pesquisa. $O$ terceiro tipo equivale ao universo das respostas apresentadas.

A partir da sentença mapeadora geral (Quadro 1), os elementos das facetas de conteúdo (contraste e complexidade) podem ser organizados de forma semelhante a uma análise matemática de combinação, produzindo ao todo nove diferentes conjuntos (A3xB3=9), que transmitem uma relação ou situação específica. A seta indica o mapeamento do conteúdo no conjunto de possibilidades de respostas, ou seja, cada uma dessas situações específicas compartilha de um racional, que apresenta a variedade de cinco respostas possíveis.

\section{Quadro 1 - Sentença mapeadora geral para a avaliação da qualidade calmante percebida em ambientes de recepção hospitalar.}

\begin{tabular}{|ll|}
\hline \multicolumn{3}{|l|}{ Em que medida a pessoa (X) avalia que o efeito das características ambientais de } \\
\hline $\begin{array}{ll}\text { (A) CONTRASTE } & \text { (B) COMPLEXIDADE } \\
\text { (A1) contraste baixo } & \text { (B1) complexidade baixa } \\
\text { (A2) contraste médio } & \text { (B2) complexidade média } \\
\text { (A3) contraste alto } & \text { (B3) complexidade alta }\end{array} \mid$ \\
\hline $\begin{array}{l}\text { RACIONAL } \\
\text { (1) nada }\end{array}$ \\
$\begin{array}{l}\text { (2) pouco } \\
\text { (3) mais ou menos }\end{array}$ \\
$\begin{array}{l}\text { (4) muito } \\
\text { (5) demais }\end{array}$ \\
\hline
\end{tabular}

Fonte: Autores da pesquisa.

O conjunto de nove cenas para apoiar o questionário online estão diretamente associadas às variáveis desta pesquisa, listadas na sentença mapeadora geral para a avaliação da qualidade calmante percebida em ambientes de recepção hospitalar, selecionado através do Google Imagem, levando em conta a manipulação sistemática de duas características dos elementos desses ambientes - contraste e complexidade - em três diferentes níveis, ou seja, a combinação de três níveis de contraste (baixo, médio, alto) com três níveis de complexidade (baixa, média, alta). (Quadro 2).

A sentença mapeadora geral, conforme Costa Filho (2014), como uma hipótese inicial da pesquisa, será analisada em relação aos resultados empíricos que devem confirmar ou contestar essa estrutura. Dessa forma, após a interpretação dos dados e na fase final, há informações suficientes para construir ou não uma nova sentença mapeadora geral como consequência direta dos resultados empíricos encontrados.

O questionário online para coletar os dados, elaborado no "Formulário Google" e baseado no Sistema de Classificações Múltiplas - que consiste em solicitar aos participantes para classificar os mesmos elementos diversas vezes, com a finalidade de compreender suas ideias sobre o objeto de estudo -, foi divulgado através de redes sociais. A escolha dessa ferramenta se deu pela conveniência de ser um meio onde se atingiria maior número de participações, não depender totalmente de verbalizações e permitir o uso de imagens.

Com relação aos procedimentos de pesquisa, inicialmente era informado que: (i) o estudo focava na avaliação visual de ambientes de recepção hospitalar; (ii) não havia resposta certa ou errada. Em seguida, o participante - após se identificar por sexo, idade, escolaridade - deveria avaliar em que medida cada ambiente de recepção hospitalar favorecia a espera por atendimento médico. Como universo de respostas, foi destacado cinco níveis, que iam de "nada" até "demais", passando pela opção "mais ou menos". 


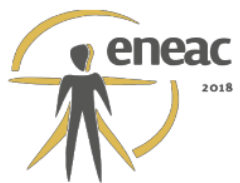

Quadro 2a - recepções hospitalares representando as relações entre as facetas de CONTRASTE e COMPLEXIDADE
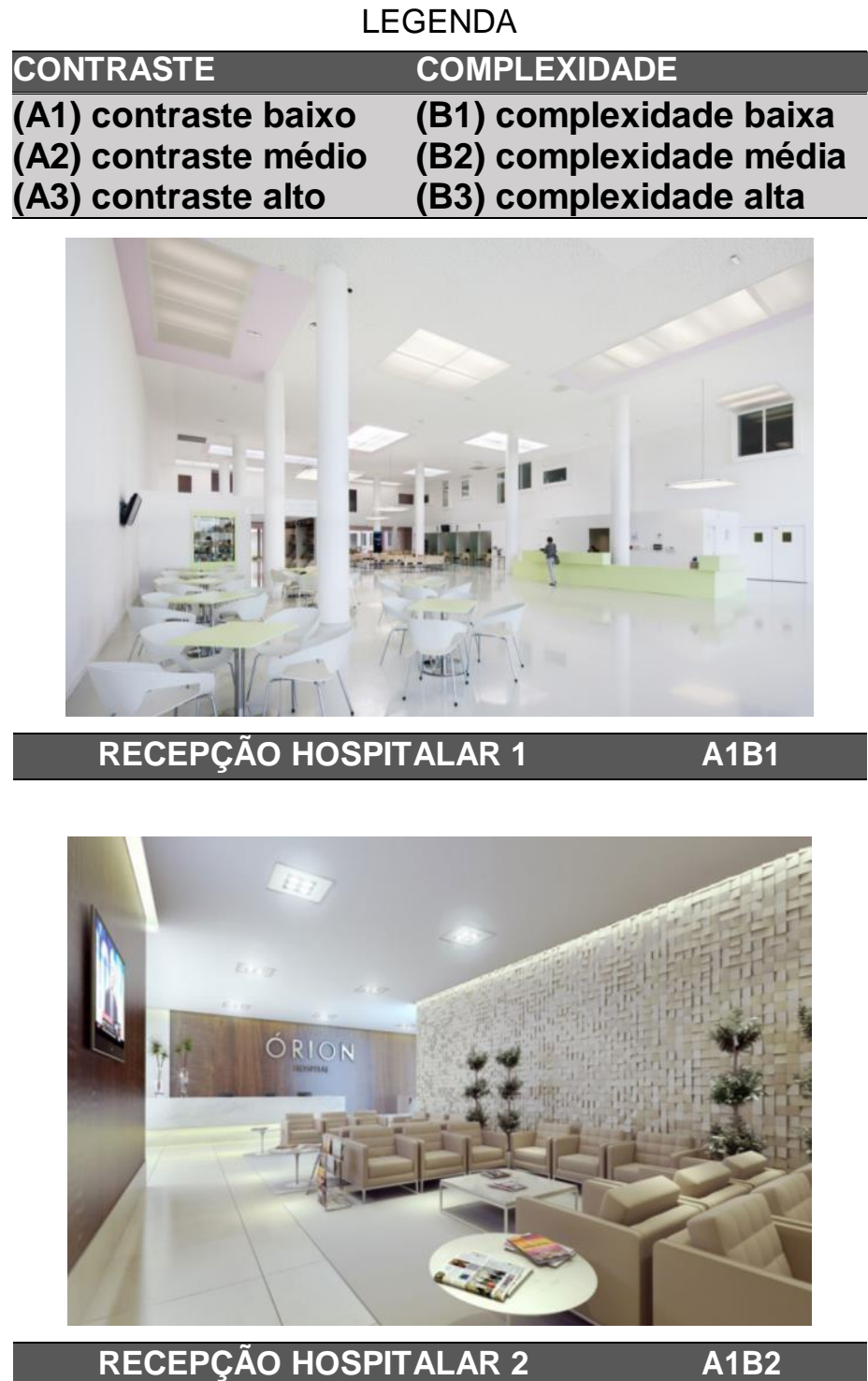

A1B2

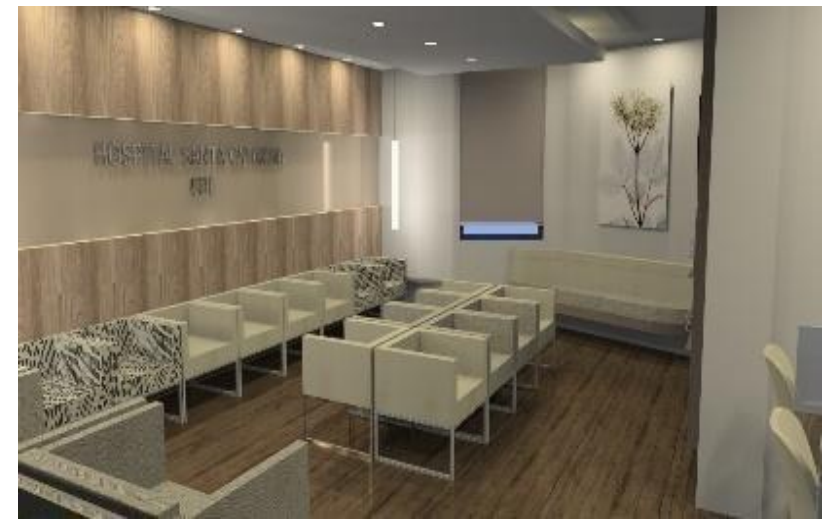

RECEPÇÃO HOSPITALAR 3

A1B3

Fonte: Google Imagem 


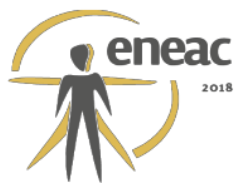

Quadro 2a - recepções hospitalares representando as relações entre as facetas de CONTRASTE e COMPLEXIDADE
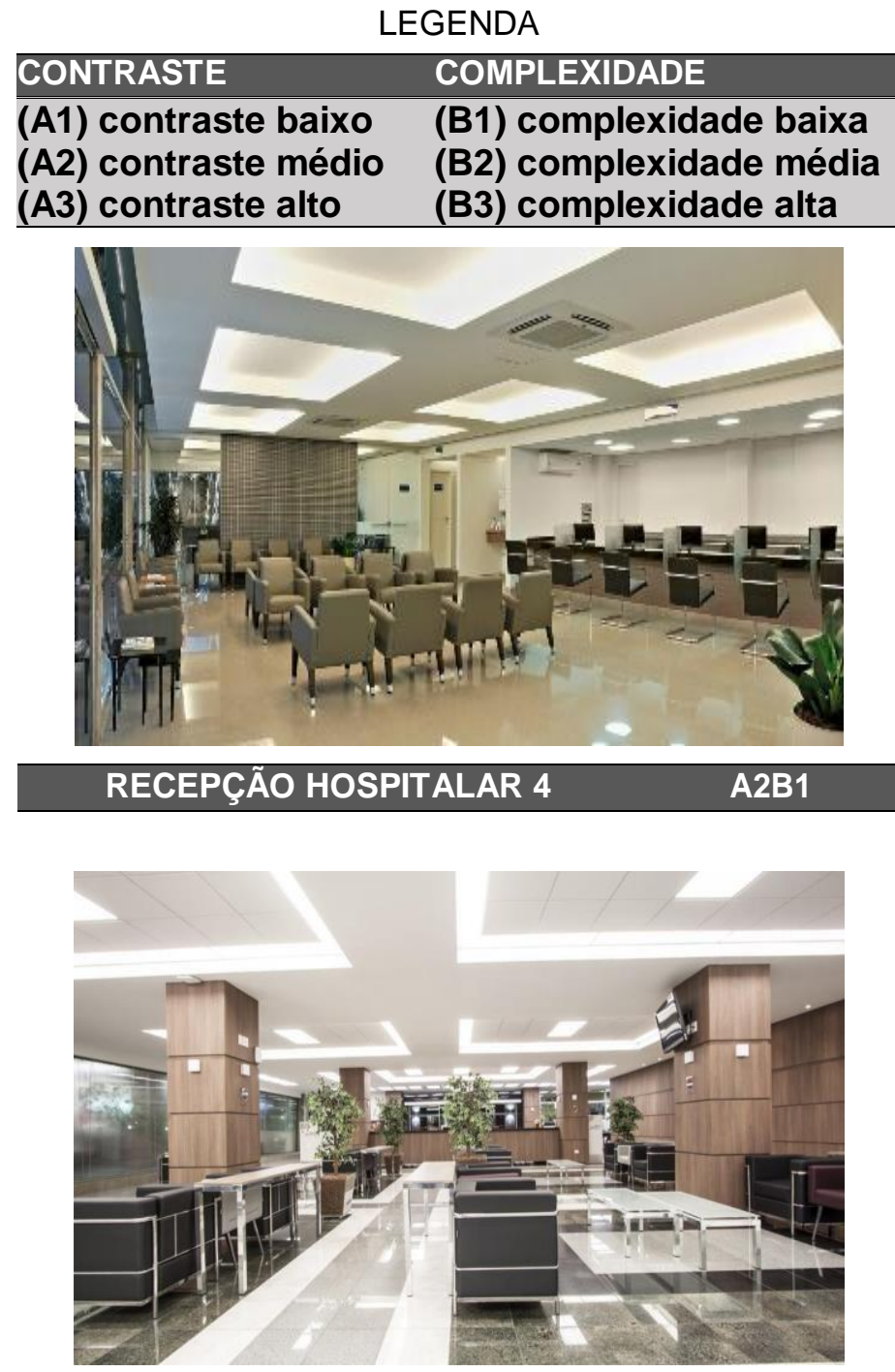

RECEPÇÃO HOSPITALAR 5

A2B2

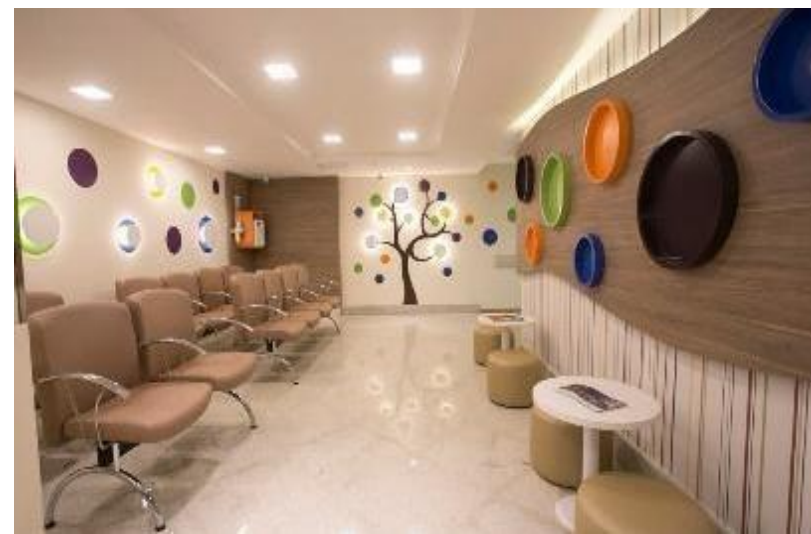




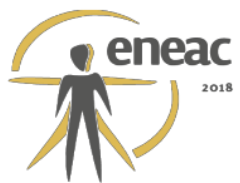

Quadro 2a - recepções hospitalares representando as relações entre as facetas de CONTRASTE e COMPLEXIDADE
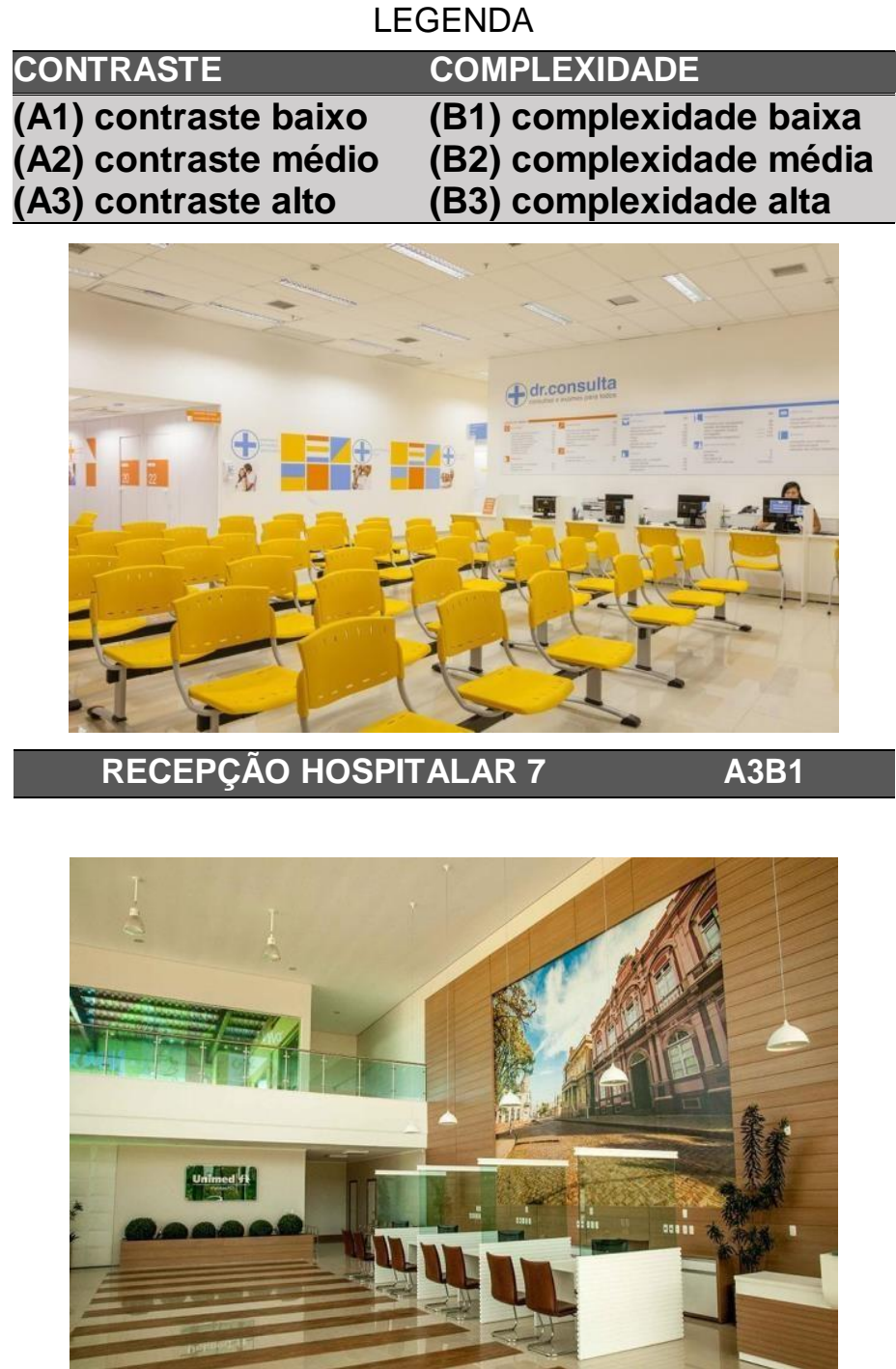

RECEPÇÃO HOSPITALAR 8

A3B2

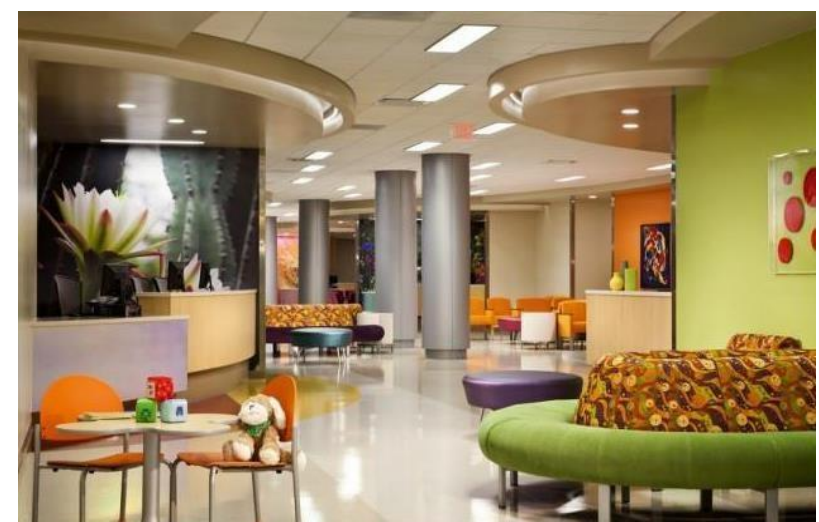

RECEPÇÃO HOSPITALAR 9

A3B3

Fonte: Google Imagem 
Ao final de uma semana, quando a pesquisa foi encerrada na Internet, contou-se com a participação de 73 sujeitos, sendo a maioria mulheres $(72,6 \%)$, entre 39 a 48 anos $(57,5 \%)$ com nível de escolaridade superior completo $(53,4 \%)$.

O processamento dos dados iniciou-se com a tabulação e posterior análise comparativa da distribuição das frequências (MARCONI; LAKATOS, 2003), buscando: (i) avaliar o efeito da coerência e da complexidade na qualidade calmante percebida; (ii) identificar as cenas julgadas como mais e menos elevadoras da qualidade calmante percebida; (iii) coligar esses resultados empíricos a um determinado nível de coerência e de complexidade.

\section{EVIDÊNCIAS EMPÍRICAS OBTIDAS}

A Tabela 1 mostra, nas linhas, a distribuição das frequências que cada uma das nove cenas utilizadas como elemento de estímulo recebeu para um determinado racional (nada, pouco, mais ou menos, muito, demais), definido com o propósito de mensurar as respostas avaliativas para a qualidade calmante percebida em ambientes de recepção hospitalar. Exibe, ainda, nas colunas, o quanto cada uma dessas cenas favorece a qualidade calmante percebida em relação ao nível de coerência e de complexidade inter-relacionados.

Tabela 1 - Frequências relativas (\%) para a qualidade calmante percebida.

\begin{tabular}{|c|c|c|c|c|c|c|c|c|c|}
\hline \multirow[b]{2}{*}{ NADA } & \multirow{2}{*}{$\begin{array}{l}\text { A1B1 } \\
8,2 \%\end{array}$} & \multicolumn{2}{|c|}{ A1B2A1B3 } & \multirow{2}{*}{$\begin{array}{c}\text { A2B1 } \\
4 \%\end{array}$} & \multirow{2}{*}{$\begin{array}{l}\text { A2B2 } \\
2,7 \%\end{array}$} & \multirow{2}{*}{$\begin{array}{l}\text { A2B3 } \\
2,8 \%\end{array}$} & \multicolumn{2}{|c|}{ A3B1A3B2 } & \multirow{2}{*}{$\begin{array}{l}\text { A3B3 } \\
4,1 \%\end{array}$} \\
\hline & & $0 \%$ & $1,6 \%$ & & & & $26,0 \%$ & $1,3 \%$ & \\
\hline POUco & $16,2 \%$ & $1,1 \%$ & $13,2 \%$ & $14,9 \%$ & $14,9 \%$ & $16,2 \%$ & $43,8 \%$ & $23,3 \%$ & $24,3 \%$ \\
\hline MAIS OU MENOS & $10,8 \%$ & $4,2 \%$ & $9,5 \%$ & $9,5 \%$ & $32,4 \%$ & $24,3 \%$ & $16,4 \%$ & $23,3 \%$ & $16,2 \%$ \\
\hline MUITO & $43,2 \%$ & $32,4 \%$ & $44,6 \%$ & $32,4 \%$ & $36,5 \%$ & $32,4 \%$ & $9,6 \%$ & $38,4 \%$ & $20,3 \%$ \\
\hline DEMAIS & $21,6 \%$ & $60,8 \%$ & $31,1 \%$ & $39,2 \%$ & $13,5 \%$ & $24,3 \%$ & $4,2 \%$ & $13,7 \%$ & $35,1 \%$ \\
\hline TOTAL & $100 \%$ & $100 \%$ & $100 \%$ & $100 \%$ & $100 \%$ & $100 \%$ & $100 \%$ & $100 \%$ & $100 \%$ \\
\hline
\end{tabular}

Fonte: Autores da pesquisa com base nos resultados obtidos.

Ao explorar os dados na tabela de distribuição das frequências (Tabela 1), pode-se verificar o efeito da coerência e da complexidade dos ambientes de recepção hospitalar na qualidade calmante percebida. Dessa forma, a hipótese inicial da pesquisa -, sobre as relações entre os elementos internos das facetas -, estabelecida na sentença mapeadora geral para a avaliação proposta, pode ser testada.

De uma maneira geral, os dados revelam os efeitos esperados nas respostas avaliativas para a qualidade calmante percebida nas nove cenas, conforme os postulados teóricos. Considerando, primeiramente, os resultados para a coerência, de um modo integrado, como mostra a Tabela 1 , a qualidade calmante é mais alta para ambientes de recepção hospitalar com coerência alta (contraste baixo), reduz para aqueles com coerência moderada (contraste médio), e menor para os ambientes com coerência baixa (contraste alto). 


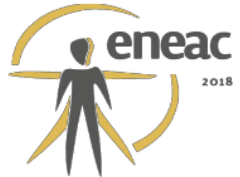

Considerando, agora, os achados empíricos para a complexidade, como mostra a Tabela 1 e também de modo integrado, a qualidade calmante é maior nos ambientes de recepção hospitalar mais complexos $(90,5 \%)$ e moderadamente complexos $(88 \%)$, quase empatados nas respostas avaliativas obtidas, e menos naqueles menos complexos.

De uma maneira específica, ainda conforme a Tabela 1, a cena de número 2 (Figura 1a), ambiente de recepção hospitalar com coerência alta (contraste baixo) e moderadamente complexo, foi percebida como o efeito que mais eleva a qualidade calmante, portanto como a mais adequada à função que o tipo de ambiente enfocado desempenha.

Cabe destacar que a característica de contraste baixo da cena, conforme referenciado, ao facilitar a compreensão, favorece a coerência que ainda reduz a incerteza e aumenta o tom hedônico (agradabilidade). O achado teve, portanto, relação com os postulados teóricos, bem como tem sido consistentemente confirmado em pesquisas.

Quanto ao fato de ser um ambiente moderadamente complexo, como também foi exposto na fundamentação teórica deste artigo, é considerado o nível ideal de estímulo, pois aumenta a calma. Pela perspectiva teórica, a qualidade calmante é aumentada através da complexidade média, uma vez que a complexidade mínima é postulada como monótona e entediante, enquanto a alta é caótica e estressante. Assim sendo, tal resultado empírico mostrou-se consistente com os postulados teóricos para a complexidade.

FIGURA 1a/b - Qualidade calmante percebida em ambientes de recepção hospitalar.

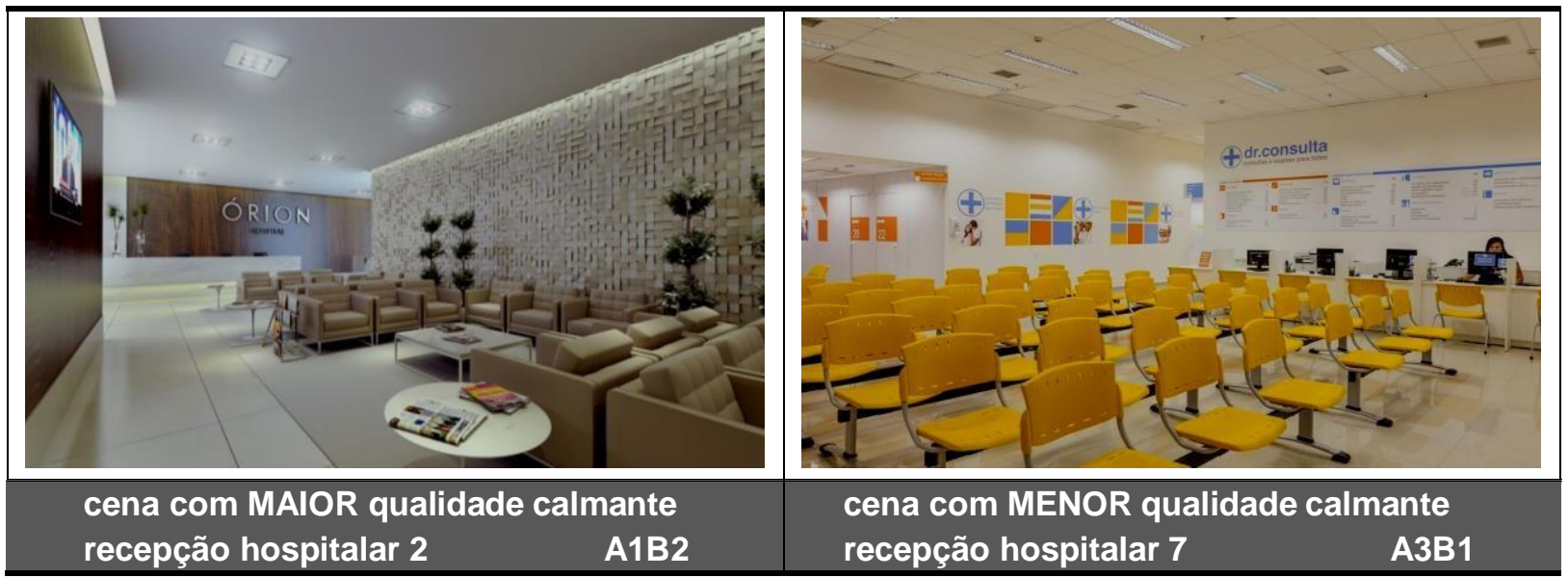

Fonte: Google Imagem

Cabe ainda trazer, como outra evidência empírica obtida, que a cena de número 7 , recepção hospitalar com coerência baixa (contraste alto) e complexidade baixa de seus elementos ambientais, foi percebida pelos participantes desta pesquisa como aquela que menos eleva a qualidade calmante percebida, portanto julgada como sendo a menos adequada à função que esse tipo de ambiente atende e, nesse contexto, altamente aflitiva.

No mais, para finalizar, cabe citar que a característica de coerência (obtida pela redução do contraste entre os elementos ambientais), a partir da análise da tabela de distribuição das frequências (Tabela 1), parece influenciar mais a elevação da qualidade calmante percebida em cenas de ambientes de recepção hospitalar do que a de complexidade. 


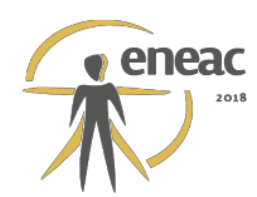

\section{CONCLUSÃO}

Como consequência direta das evidências empíricas, que confirmaram a hipótese inicialmente formulada nesta pesquisa, a sentença mapeadora geral para a avaliação da qualidade calmante percebida em cenas de ambientes de recepção hospitalar (Quadro 1) foi confirmada. Logo, há consistência de que o mapeamento entre três diferentes níveis das características de coerência e complexidade dos elementos ambientais de recepções hospitalares são determinantes para o tipo de avaliação proposto.

Ao analisar a qualidade calmante percebida em cenas de ambientes de recepção hospitalar, apurou-se que a qualidade calmante percebida é elevada a partir do efeito da coerência alta (contraste baixo) e da complexidade média dos seus elementos ambientais. Num sentido inverso, é reduzida para o efeito da coerência baixa (contraste alto) e da complexidade baixa, embora o postulado teórico recomende esse nível de complexidade para a clama percebida.

Esses resultados empíricos, contudo, não devem ser tomados de uma maneira simplista, pois se tratam de uma compreensão para o tipo de elemento de estímulo apresentado aos participantes abordados como suporte para as avaliações, os respondentes participantes, e o local e a época em que a investigação foi realizada.

\section{REFERÊNCIAS}

COSTA FILHO, L. L.; OLIVEIRA, I. F.; YOKOYAMA, S. A. A qualidade percebida da paisagem midiática do comércio varejista de Caruaru. In: MONT'ALVÃO, C.; VILLAROUCO, V. (Orgs.), Um novo olhar para o projeto: 3: a ergonomia do ambiente construído. Recife: Editora UFPE, 2016.

COSTA FILHO, L. L. O enfoque da Teoria das Facetas na avaliação de lugares. In: MONT'ALVÃO, C.; VILLAROUCO, V. (Orgs.), Um novo olhar para o projeto, 2: a ergonomia no ambiente construído. Recife: Ed. UFPE, p. 11-26, 2014.

KAPLAN, Stephen. Perception and landscape: conceptions and misconceptions. In: NASAR, J. L. (Ed.). Environmental aesthetics: theory, research, and application. New York: Cambridge University Press, 1988. p. $45-55$.

MARCONI, M. A.; LAKATOS, E. M. Fundamentos de metodologia. 5. ed. São Paulo: Atlas, 2003.

NASAR, J. L. The effect of sign complexity and coherence on the perceived quality of retail scenes. In: NASAR, J. L. (Ed.), Environmental aesthetics: theory, research, and application. New York: Cambridge University Press, 1988.

The evaluative image of places. In: WALSH, W. B.; CRAIK, K. H.; PRINCE, R. H. 2nd ed. (Eds.). Person-environment psychology: new directions and perspectives. New Jersey: Lawrence Erlbaum Associates, 2000. p. 117-168

RUSSEL, J. Affective appraisals of environments. In: NASAR, J. L. (Ed.). Environmental aesthetics: theory, research, and application. New York: Cambridge University Press, 1988. p. 120-129.

VILLAROUCO, V. Tratando de ambientes ergonomicamente adequados: seriam ergoambientes? In: MONT'ALVÃO, C.; VILLAROUCO, V. (Orgs.), Um novo olhar sobre o projeto: a Ergonomia do Ambiente Construído. Teresópolis: 2AB, 2011. p.25-46.

WOHLWILL, J. Environmental aesthetics: The environment as a source of affect. In: ALTMANN, I.; WOHLWILL, J. (Eds.), Human behavior and environment, v.1, 37-86, 1976. 